\title{
LA VOZ BIZARRO Y SUS INSÓLITAS FORTUNAS LITERARIAS
}

\begin{abstract}
Resumen. Se estudia la presencia del vocablo bizarro en el español actual en su acepción como «raro, extravagante», que se impone sobre los significados recomendados por la RAE. Se presentan fenómenos culturales globales como Bizarro fiction, Bizarro World y Bizarro del DCComics, que han influido en su desplazamiento semántico: bizarro adquiere un uso relacionado con la creación artística. Su etimología se traza enfocándonos en el «loco bizarro» del Quijote (1615), que permite contrastar la voz italiana bizzarro con bizarro y bizarre, castellano y francés, respectivamente. El último dio origen al cultismo bizarre en el inglés del XVII que, según Merriam-Webster Dictionary, en torno a 1971 pasó a bizarro en la variante informal del inglés norteamericano.
\end{abstract}

Palabras clave: RAE, bizarro, bizarre, DCComics, Bizarro fiction, Cervantes, Olga Tokarczuk.

\section{Olga Tokarczuk y Opowiadania bizarne (2018)}

El 18 de abril de 2018 salió a la luz un nuevo libro de Olga Tokarczuk, cuyotítuloa primera vista-Opowiadaniabizarne-resultaextrañoa loslectores polacos. El epíteto (bizarne) -con el cual la autora caracteriza la colección de diez relatos (opowiadania) - hasta ahora no ha sido documentado en los diccionarios de lengua polaca. Tokarczuk ha acostumbrado a sus lectores a ingeniosos títulos que albergan algún misterio fundamentado en el uso de neologismos o de voces olvidadas. También esta vez la contraportada explicita que las historias que el libro recoge son «imprevisibles, extrañas, hermosas» (nieprzewidywalne, dziwne, piękne) y que a la vez «despiertan temor» (budzace grozę): «El lector no puede estar seguro de adónde le llevará cada una de las historias. Olga Tokarczuk nos saca de la zona de confort, indicando que el mundo se vuelve cada vez más ininteligible. La palabra

\footnotetext{
* Uniwersytet Wrocławski.
} 
francesa bizarre significa raro, pero también divertido y extraordinario» ${ }^{1}$ (Tokarczuk, 2018: contraportada).

La autora en una entrevista publicada en la revista Tygodnik Powszechny subraya que - para el título de su último libro- le faltaba una palabra polaca que significase lo mismo que bizarre en francés: «No me contentaba con: 'extrañas' (dziwne), 'raras' (dziwaczne), 'estrafalarios' (cudaczne). En la lengua polaca en el lugar de la palabra bizarne solo había un rictus de rostro con las cejas arqueadas hacia arriba manifestando incredulidad, un ligero choque y ambivalencia» (Tokarczuk y Kubisiowska, 2018). Olga Tokarczuk inscribe sus «relatos bizarros» en la tradición del cuento fantástico de Edgar Allan Poe, pero a la vez puntualiza:

Todos son un comentario a la realidad, cada vez más «bizarra» (bizarnej), son un comentario a lo que leo en los diarios y veo por la tele. Aunque tengan forma fantástica, sin embargo están enraizados fuertemente en todo lo que hablamos, en todo de lo que tenemos miedo, en todo lo que nos preocupa (Tokarczuk y Kubisiowska, 2018).

A nuestro parecer, con esta declaración la escritora polaca quiere marcar distancia frente a uno de los recientes subgéneros de la literatura fantástica en expansión desde Estados Unidos: bizarro fiction ${ }^{2}$.

\section{Bizarro fiction (2005)}

En 2005 tres editoriales independientes americanas -Raw Dog Screaming Press, Afterbirth Books, Eraserhead Press- emplearon el adjetivo bizarro como etiqueta de marca para un nuevo estilo de narraciones que habían estado publicando desde hacía una década, según detalló Rose O'Keefe, la editora y propietaria de Eraserhead Press, entrevistada en 2010 por la revista Fantasy Magazine ${ }^{3}$. El término Bizarro fiction ha sido definido recientemente por Bernice M. Murphy, autora de Key Concepts in Contemporary Popular Fiction ${ }^{4}$.

1 Todas las traducciones, si no se indica de otra manera, son de las autoras del artículo.

${ }^{2}$ Sobre bizarro fiction en la literatura polaca ver Adam Mazurkiewicz (2016) y en la literatura española, R. R. López (22 de enero de 2018).

3 «So, in 2005, the three companies decided to officially label this style of writing Bizarro. Basically, we want bizarro to be the literary equivalent to cult movies. Our books are quirky, campy, freaky, funny, lewd, rude, and just out there. It's been growing exponentially ever since» (Henderson, 2010).

${ }^{4}$ Murphy (2017: 12): «widely accepted definition of term such as [...] 'Bizarro Fiction' $[\ldots]$ are, at the time of writing, not yet fixed». 
BIZARRO FICTION is characterized by its surreal, absurdist, grotesque and often comical stylistic and tonal excess. The sub-genre (an off-shoot of weird fiction / fantasy) has its origins in the output of a number of small presses specializing in cult fiction [...] Bizarro fiction thrives on pushing plots and themes to their most outlandishly grotesque conclusions, and many of the titles are notable for their deliberately eye-catching ridiculousness. [...] There are now websites devoted to Bizarro Fiction (such as bizarrocentral.com), short story collections, fan events and magazines (Murphy, 2017: 22).

El diccionario oxoniense de la lengua inglesa, disponible en línea, especifica que bizarro es un equivalente informal norteamericano («North American informal») de la voz bizarre («very strange or unusual») cuyos orígenes, a su vez, se remontan a «Mid 17th century: from French, from Italian bizarro 'angry', of unknown origin» (Oxford: 'bizarre'). El origen de la forma bizarro según la misma fuente es mucho más reciente: «1950s: alteration of bizarre, perhaps from the name of a character in DC Comic' Superman comic books» (Oxford: 'bizarro') $)^{5}$.

\section{Bizarro y Bizarro World (DC Comic 1958 y 1960)}

La Wikipedia informa que Bizarro, personaje del cómic, apareció por primera vez en el núm. 68 del Superboy, en octubre de 1958, como una versión alternativa del protagonista: su doble imperfecto producido por un rayo duplicador ${ }^{6}$. Bizarro, como clon y antagonista a la vez, hizo carrera en las series relacionadas con el Superman adulto. Con los años los Bizarro han ido habitando el planeta conocido con el nombre de Bizarro World introducido en la entrega núm. 263 de la serie Action Comics, en abril de 1960. Se trata de una versión contemporánea del mundo al revés al uso de la cultura popular norteamericana que se está expandiendo globalmente a través de los tebeos, películas, juegos, etc. Tan solo los autores de la versión castellana del artículo dedicado a Bizarro en la Wikipedia consideraron oportuno referirse al origen de su nombre:

El nombre Bizarro deriva de la palabra inglesa bizarre que significa extraño o raro y no se relaciona con el significado tradicional en español, donde la palabra bizarro se usa como adjetivo para describir a alguien o algo que tiene porte, gallardía o está muy bien plantado (Wikipedia [español]).

${ }^{5}$ Bizarro (Merriam-Webster): «characterized by a bizarre, fantastic, or unconventional approach»; «alteration of bizarre»; «First known use: 1971».

${ }^{6}$ Véase la versión inglesa de la Wikipedia y también la página web de DC Comics sobre el personaje Bizarro. 


\section{La palabra bizarro en España}

La voz bizarro está documentada en la lengua española desde el siglo XVI. El Corpus del Nuevo Diccionario Histórico del Español (Instituto de Investigación Rafael Lapesa de la RAE, 2013) recoge 2407 casos de su uso en 940 documentos ${ }^{7}$. El Diccionario de la lengua española (RAE, 2014a), en su edición del Tricentenario, indica dos significados del adjetivo bizarro, rra: (1) valiente en el sentido de arriesgado; (2) generoso, lucido, espléndido. Estas dos definiciones corresponden a grandes rasgos con los significados anotados por el Diccionario de Autoridades (RAE, 1726: 612), respectivamente: «Generoso, alentado, gallardo, lleno de noble espíritu, lozanía y valor»; «Vale también lucido, muy galán, esplendido y adornado».

Sorprende que bizarro figure entre las palabras más consultadas en el Diccionario de la lengua española disponible en línea desde 2003. A partir del año 2012 la Real Academia Española empezó a usar las herramientas del Google Analytics para analizar los resultados en las búsquedas a través del Internet. Los primeros análisis fueron publicados en un amplio informe «La tecnología al servicio de la palabra. Últimos datos sobre 392 consultas y accesos a los diccionarios, aplicaciones y formularios de la página web de la RAE»:

A lo largo del pasado año 2013, el DRAE en línea, disponible en http://www.rae.es, ha recibido una media de consultas de cuarenta millones mensuales. El Departamento de Tecnología de la RAE hace un seguimiento puntual de todo ello, contando, además, con indicadores de referencia externos como Google Analytics. No solo podemos determinar así la cifra total de consultas, sino también procedencia geográfica, las rutas que han seguido hasta llegar a formularse $y$, por supuesto, qué palabras han despertado más curiosidad entre los usuarios de nuestro portal (RAE, 2014b: 3).

En la lista de las palabras consultadas con mayor frecuencia en el

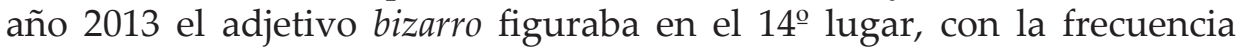
de 185 262. Lo precedían, en orden ascendente: paradigma, ver, estar, dar, hola, ser, amor, a, hacer, ir, haya, haber, cultura (RAE, 2014b: 9). La palabra cultura alcanzó casi medio millón de consultas (464 019). Bizarro era el número uno entre los adjetivos, seguido por inherente con tan solo 116028 consultas (el 42 de la lista).

Sin embargo, las «Estadísticas de las consultas realizadas a los formularios, aplicaciones y diccionarios ofrecidos por la página web de la RAE durante enero de 2014 e informe de Google Analytics», incluidas

7 Todas las consultas a las obras académicas de la RAE se han hecho a través de la página web: <https://www.rae.es $>$. 
en la misma entrega del BILRAE (RAE, 2014b: 51-60), anticipaban una nueva dinámica que hizo subir bizarro al $5^{\circ}$ puesto de la lista con 23135 consultas desde 18600 IPs; por su parte, cultura figuraba en segundo lugar con 29658 consultas desde 15020 IPs. Encabezaba la lista el verbo inferir con 46397 desde 8611 IPs. Si tomáramos en cuenta el número de los usuarios (es decir los IPs registrados), bizarro encabezaría el ranking de consultas. A lo largo del año 2014 cultura volvió a tomar la delantera, pero bizarro no se quedó corto y subió al segundo lugar según informaba Babelia con fecha del 11 de octubre de 2014, anunciando la pronta aparición de la $23^{\mathrm{a}}$ edición del Diccionario de la lengua española. Se preguntó a los académicos: "¿Por qué cultura es la palabra más buscada? 》 (Heras Bretín, 2014). Pedro Álvarez de Miranda, director de la nueva edición del DLE, confesó que la alta frecuencia de cultura (51 085 consultas desde 15085 IPs) le resultaba «chocante». Aun más sorprendente era el impacto de bizarro «con 35172 búsquedas de 21645 usuarios». El número de los IPs registrados indicaba que la palabra bizarro fue consultada con menos frecuencia «pero por más personas, que cultura, consultada por poco más de 15000 personas» (Heras Bretín, 2014). El caso de bizarro -concluía la autora del artículo-correspondía a modas que hacían reaparecer palabras que «estaban en desuso»:

Entre los académicos surge la duda de si se le estará dando el uso correcto: valiente, generoso, lucido, espléndido. Álvarez de Miranda se teme que se haya recuperado por la influencia del inglés y se esté utilizando como estrafalario, raro, estrambótico, lo que responde a la traducción de la palabra inglesa bizarre (Heras Bretín, 2014).

No se trataba de una moda pasajera, porque cultura y bizarro corrían parejas y volvieron a ser noticia al año siguiente.

El protagonismo de bizarro era notorio. Al final de 2014, Carmen Mañana en Icon, revista mensual masculina de El País, abogó por erradicar bizarro del castellano (junto con otras seis palabras) para librarse de «granos lingüísticos» cuyo «uso y abuso» merecía como mínimo «cierta reflexión»; todo ello con el objetivo de ir mejor en el año 2015 que en el 2014. Sobre bizarro apuntó irónicamente:

Desde las críticas de música más pretenciosas hasta las conversaciones que comienzan en la barra de bares pseudomodernos y pretenden terminar en camas flanqueadas por pilas de libros a modo de mesilla de noche, el término bizarro ha sido mal empleado desde hace un lustro. Según la RAE es «algo o alguien valiente» o, en su segunda acepción, «generoso, lucido o espléndido». Algo bizarro no es algo raro. Ese es su significado en inglés, no en castellano. «Tío, dice que le gusta Víctor Manuel, qué bizarro». Desde luego confesarlo lo es, pero en su primera acepción. Hay personas que sostienen que da igual, que valiente es sinónimo de raro. Ellos sí que lo son (Mañana, 2014). 
No obstante, el 3 de noviembre de 2015 la palabra volvía a los titulares de El País: «Cultura y bizarro abren la lista de palabras más buscadas en la versión online»

[...] en concreto desde el 21 de octubre de 2014, cuando se presentó la $23^{\text {a }}$ edición en papel. [...] Cultura repite el primer puesto (ya lo hizo el año anterior), con 340052 búsquedas en estos 12 meses. [...] La razón de que cultura sea habitualmente la más demandada obedece, según [Darío] Villanueva, «a que es un término complejo que últimamente se usa en contextos sorprendentes, incluso a veces contradictorios. Aunque es un término positivo, se habla por ejemplo de la cultura de la droga o de la cultura del dinero». Sorprendente es también el italianismo que se ha colado en segunda posición de octubre a octubre: Bizarro (277 566 búsquedas). A ello han ayudado los resultados en países como Colombia, Argentina y México. Villanueva lo explica: «Me dicen que se puso de moda entre los jóvenes» (Morales, 2015).

A los cinco días Jaime Rubio Hancock en Verne, web de El País, se propuso explicar: «La razón por la que bizarro es una de las palabras que más buscamos en el diccionario» (Rubio Hancock, 2015). La respuesta era obvia: «Cientos de miles de personas buscan la palabra en el diccionario online de la RAE para comprobar que no significa raro, sino valiente» (Rubio Hancock, 2015). Se sirvió de un testimonio personal:

Muchos no sabemos usar la palabra bizarro. Bueno, yo ahora sí. Pero hablo en primera persona porque hace poco metí la pata en un artículo: escribí bizarro como sinónimo de raro, sórdido, que es su significado en inglés y en francés. El diccionario panhispánico de dudas afirma que este uso es un «calco semántico censurable», una expresión que hace que me sienta terriblemente avergonzado por mi error. No se puede ir por la vida haciendo cosas censurables. Además, mi equivocación fue corregida por una comentarista a la que solo le faltó arrojarme un cenicero a la cabeza (y con razón, tampoco lo voy a negar) (Rubio Hancock, 2015).

A continuación anticipaba que «es posible que la RAE acabe admitiendo una tercera acepción de bizarro y aceptando que también significa raro porque, al fin y al cabo, así es como la mayoría lo usa» (Rubio Hancock, 2015).

Cuando el 12 de marzo de 2016 el $A B C$ informó que «cada mes se registran 60 millones de visitas en la web de la RAE, con más de 10 millones de usuarios, dato muy actual, del pasado febrero», las palabras cultura y bizarro seguían siendo las más consultadas, respectivamente, la primera en España y la segunda en México, Argentina y Colombia. Hasta se aventuró una explicación: «Algunos países quieren diferenciar el bizarro del español frente a su acepción inglesa (todos menos España)» (García Calero, 2016). El año 2016 se dispararon las consultas «con un crecimiento brutal -comunicaba El País el 28 de enero de 2017- del 58\% respecto a 2015, hasta situarse en 800 millones» (Morales, 2017). La lista de 
palabras más consultadas incluía bizarro ${ }^{8}$. El año 2017 sumó 750 millones de consultas, y bizarro -según informó la RAE (2018) a través de su página web- figuraba entre «las más habituales».

Fue la Fundación del Español Urgente BBVA la primera en adelantar a través del Twitter que «bizarro puede emplearse con el significado de 'cosa extraña, rara, insólita'»(@Fundeu, 8 de noviembre de 2016). La argumentación era la siguiente:

El término bizarro puede emplearse, en alusión a una cosa, con el significado de 'extraño, raro, insólito', tal como recoge el Diccionario de americanismos, de las Academias de la Lengua. Aunque tradicionalmente se ha censurado este uso por considerarse influencia del francés, se encuentra extendida desde hace tiempo, y así lo refleja el diccionario mencionado, que indica que se trata de una voz utilizada principalmente en Puerto Rico, Chile y Argentina. Este valor se une así a los ya registrados en el Diccionario académico de 'valiente' y de 'generoso, lucido, espléndido'. También aparece recogido en el Diccionario del español actual, en el de mexicanismos de la Academia Mexicana de la Lengua y en el Diccionario de uso del español, de María Moliner, que ya en su primera edición señalaba que se empleaba con el sentido de 'extravagante, sorprendente o gracioso'. Según estas definiciones, no serían rechazables frases como las siguientes: «Son leyes bizarras, raras, exóticas, que se explican únicamente en el contexto autóctono», «Una creativa, austera y bizarra publicidad que está haciendo hablar a todos en la Argentina» o «La foto más bizarra de Hillary Clinton» (Fundéu, 2016).

El equipo Verne dos días más tarde alentaba a sus seguidores: «Por fin puedes usar bizarro para decir 'raro'. La extensión de su uso permite 'presagiar que acabe por incorporarse al diccionario académico en futuras revisiones' según la RAE» (Rodríguez-Pina, 2016). La autora consultó la RAE (informando al margen: «el Departamento de 'Español al día' de la RAE resuelve dudas a través de Twitter en @RAEinforma») cuyo representante reconocía

que «en los últimos tiempos ha comenzado a revitalizarse en el uso un sentido muy distinto, por influjo de otras lenguas como el inglés o el francés, en las que el término equivalente significa 'raro, extravagante'». La institución lo considera sin embargo «un calco semántico innecesario», porque en español existen raros, extravagantes, y por esa razón no lo ha incluido aún en el diccionario. El término tal y como lo recoge el diccionario de la RAE, en palabras de la Academia, está «restringido a la lengua culta y literaria, donde no deja de presentar un cierto regusto arcaizante» (Rodríguez-Pina, 2016).

Por cierto, en menos de dos meses @RAEinforma (2 de enero de 2017) tuiteó: «Aunque DLE no recoge bizarro como 'raro', la extensión de este uso hace presagiar que se incluirá». En los tuits anteriores se solía incluir

${ }^{8}$ Ver también la aportación sobre bizarro de Equipo Verne (2016). 
el enlace al Diccionario panhispánico de dudas cuya indicación era tajante: «Debe evitarse su empleo con el sentido de 'raro o extravagante', calco semántico censurable del francés o del inglés bizarre» (RAE y ASALE, 2005). Al final del año @RAEinforma (7 de diciembre de 2017) confirmaba a un usuario que la palabra había tomado recientemente el significado de «raro, extravagante» y que él mismo podía «enviar la sugerencia al DLE» a que se amplíe su significado.

A principios del año 2018 «el desplazamiento semántico de bizarro» volvió a Twitter (@RAEinforma, 22 de enero de 2018) para responder con fecha del 23 de enero: «es posible que acabe siendo reconocida esta nueva acepción en el diccionario académico» ${ }^{9}$. Desde la Universidad de León llegaba a los tuiteros una captura de pantalla con la historia de la palabra bizarro que el Departamento de Filología Hispánica y Clásica había colgado en su Facebook el pasado 3 de octubre. Incluía una observación muy puntual: «Por cierto, no hay que descartar que en el cada vez más habitual uso de este [...] valor (el de 'raro') haya influido el personaje de cómic Bizarro (creado por el escritor Otto Binder)».

\section{5. «Loco bizarro» según Cervantes (Don Quijote de la Mancha, $2^{\mathrm{a}}$ parte, cap. XVIII)}

Jean Canavaggio, célebre cervantista francés, dedicó en 2015 un estudio a la expresión «loco bizarro» con la cual don Diego, el Caballero del Verde Gabán, -dirigiéndose a su hijo, don Lorenzo- se refiere a don Quijote, a quien ha invitado a su casa, en el Capítulo XVIII de la Segunda parte de Don Quijote de la Mancha. Se traen a colación las versiones francesas de la novela cervantina, desde la de François Rosset, quien tradujo la Segunda parte en 1618, hasta la más reciente -la versión revisada de la Bibliothèque de La Pléyade, publicada en 2012- firmada por el mismo Canavaggio junto a Claude Allaigre y Michel Moner. Todo aquello para argumentar que don Quijote según Cervantes es «un fou singulier», tal como Francisco Rico anota el texto a pie de página en la edición del Instituto Cervantes -«un curioso loco» (Cervantes, 1998: 776)remitiendo al estudio del lingüista italiano Gian Luigi Beccaria, Spagnolo

9 Al recibir el 30 de abril de 2018 una nueva consulta al respecto, \#RAEconsultas concluía con fecha del 1 de mayo: «Su extensión en el actual justifica el levantamiento de la censura tradicional»; es de esperar que pronto DLE actualizará la entrada correspondiente a bizarro. 
e spagnoli in Italia. Riflesi ispanici nella lingua italiana del Cinque e del Seicento del año 1968 (Canavaggio, 2015: 23).

Canavaggio confiesa «el olvido cometido en 2001», fecha en que se publicó la primera edición del Quijote en La Pléyade y que sería corregido «con notable retraso», en 2012. Por eso se propone «acrisolar el significado exacto que reviste el apodo loco bizarro» recurriendo a Beccaria quien:

[...] aclara [...] la trayectoria semántica del italiano bizzarro, así como [...] vicisitudes, consecutivas a sus intercambios que se produjeron entre ambas penínsulas, dentro de un constante vaivén entre dos áreas lingüísticas y culturales. Bizzarro [...] quiere decir primero «colérico» $y$, después, «valiente», ha conservado esta segunda acepción en castellano, antes de tomar la de «gallardo», «elegante», «apuesto». No obstante, aun antes de que el italiano importe a su vez desde España esta acepción derivada, bizzarro ofrece un tercer sentido, que pertenece al léxico artístico y está relacionado con la afición prebarroca y barroca a la pompa y la magnificencia, en beneficio de todo lo que resulta no sólo ornamental, sino ingenioso y hasta hiperbólico. Viene a ser entonces sinónimo de «curioso", «extravagante», «peregrino». Esta acepción, pronto adoptada por el francés, no sigue la misma trayectoria en castellano, ya que Cervantes, al menos en su época, parece haber sido uno de los pocos en tenerla en cuenta, sin duda a consecuencia de su estancia durante cinco años en Italia de la que conservará una marcada huella. [...] el Diccionario de Autoridades no recogerá esta acepción, ni tampoco ninguno de los demás diccionarios publicados posteriormente por la Real Academia Española (Canavaggio, 2015: 22-23).

\section{A modo de conclusión: bizarny y bizarro (2018)}

Se vislumbra -a través de los tuits emitidos por la RAE en los últimos meses- que los académicos españoles pronto aprobarán como normativo aquel "peregrino» ${ }^{10}$ significado de bizarro, documentado por Cervantes ya en el año 1615. Resulta al menos "curioso», es decir, «bizarro» (como la locura del Quijote) que bizarro vuelva a España -y al español normativo- de la mano de Bizarro, personaje del cómic -una posmoderna mutación de los libros de caballerías con el Superman en el rol del caballero andante. Al volver recupera aquel tercer sentido «de extravagante, insólito o alternativo» (Rodríguez-Pina, 2016) que hace eco del léxico artístico del siglo XVII que a la perfección dominó Cervantes. En contra de lo que piensan los tuiteros puristas no se está «cargando una palabra tan bonita por ignorancia y vergüenza y el típico complejo con el

${ }^{10}$ Aquí con varios de sus significados, citamos el DLE en línea: «Que pasa de un lugar a otro», «Que procede de un país extraño», «Extraño, especial, raro o pocas veces visto», «Adornado de singular hermosura, perfección o excelencia» (RAE, 2014a). 
idioma inglés» ${ }^{11}$. Todo lo contrario. Desde la RAE se ha observado que el empleo de bizarro «es especialmente frecuente en documentos que hacen referencia a producciones artísticas, en las que la voz adquiere un uso casi técnico» (Rodríguez-Pina, 2016).

No creemos casual que Olga Tokarczuk, Premio Booker Internacional 2018, haya inventado el neologismo bizarne recurriendo al bizarre francés para emplear este ya global concepto con el fin de advertir al lector sobre el insólito carácter de lo que se narra en Opowiadania bizarne (Tokarczuk, 2018). La escritora polaca-que parece instintivamente repetir el gesto de Cervantes en la fórmula bimembre del título (tal como lo han hecho antes muchos otros novelistas al reunir en un libro varias narraciones) dándoles a sus historias el nombre de bizarras- pregunta: «¿Qué es aquella sensación de extrañeza y de dónde viene? ¿La extrañeza es una característica del mundo o tal vez está en nosotros?» (Tokarczuk, 2018: contraportada).

\section{Bibliografía}

CANAVAGGIO, J. (2015). «Don Quijote, loco bizarro», Monteagudo, 20, 15-27 [también en línea] <http://revistas.um.es/monteagudo/article/view/243191>, fecha de consulta: 26 de agosto de 2018.

DC Comics (Estados Unidos). «Bizarro», DC Comics [en línea] <https://www.dccomic.com/characters/bizarro $>$, fecha de consulta: 26 de agosto de 2018.

CERVANTES DE, M. (1998). Don Quijote de la Mancha, F. RICO (dir.). Edición del Instituto Cervantes, Barcelona: Instituto Cervantes / Crítica [también en línea] <https://cvc.cervantes.es/literatura/clasicos/quijote/default.htm>, fecha de consulta: 26 de agosto de 2018.

FUNDÉU (@Fudeu). «\#puestaapunto: Bizarro puede emplearse con el significado de 'cosa extraña, rara, insólita'», Twitter, 8 de noviembre de 2016, hora 11:25 a.m.

FUNDÉU (2016). «Bizarro también significa'raro, extravagante'» [en línea]<https:// www.fundeu.es/recomendacion/bizarro-significa-raro-extravagantevaliente>, fecha de consulta: 26 de agosto de 2018.

GARCÍA CALERO, J. (2016). "Cultura, gitano, 'cocreta', procrastinar, bizarro y plebiscito, las palabras más buscadas», $A B C, 12$ de marzo de 2016 [en línea] $<$ https://www.abc.es/cultura/abci-cultura-gitano-cocreta-procrastinar-bizarro-y-plebiscito-palabras-mas-buscadas-201603120209_noticia.html>, fecha de consulta: 26 de agosto de 2018.

HENDERSON, R. (2010). «Bizarro Fiction 101: Not Just Weird for Weird's Sake», Fantasy Magazine [en línea] <http://www.fantasy-magazine.com/non-fiction/

11 Tuitera anónima con el apodo @goldmemories, 20 de enero de 2017, al comentar el tuit de la RAE (2 de enero de 2017). 
bizarro-fiction-101-not-just-weird-for-weirds-sake>, fecha de consulta: 26 de agosto de 2018.

HERAS BRETÍN DE LAS, R. (2014). «¿Por qué cultura es la palabra más buscada?», El País. Babelia, 1194, 11 de octubre de 2014, 4 [en línea] <https://elpais. com/cultura/2014/10/09/babelia/1412865082_128699.html>, fecha de consulta: 26 de agosto de 2018.

INSTITUTO DE INVESTIGACIÓN RAFAEL LAPESA DE LA REAL ACADEMIA ESPAÑOLA (2013). Corpus del Nuevo Diccionario Histórico del Español (CDH) [en línea] <http://web.frl.es/CNDHE>, fecha de consulta: 26 de agosto de 2018.

LÓPEZ, R. R. (22 de enero de 2018). «¿Qué es la literatura bizarra? 8 libros para entender el género literario bizarro», Historias que no contaría a mi madre [en línea] <https://historiasquenocontariaamimadre.com/literatura-bizarra>, fecha de consulta: 26 de agosto de 2018.

MAÑANA, C. (2014). «Siete palabras que debemos erradicar del castellano en 2015», El País. Icon, 12, 10 de diciembre de 2014 [en línea] <https://elpais.com/ elpais/2014/12/09/icon/1418146340_120789.html>, fecha de consulta: 26 de agosto de 2018 .

MAZURKIEWICZ, A. (2016). «Dziwność istnienia. O nurcie bizarro fiction w polskiej literaturze», Literatura i Kultura Popularna, 22, 61-74 (DOI: 10.19195/08677441.22.4).

MERRIAM-WEBSTER (Estados Unidos). «Bizarre» / «Bizarro», Merriam-Webster Dictionary [en línea] <https://www.merriam-webster.com/dictionary>, fecha de consulta: 26 de agosto de 2018.

MORALES, M. (2015). "¿Haya o halla? Responde el Diccionario?», El País, 3 de noviembre de 2015 [en línea] <https://elpais.com/cultura/2015/10/26/actualidad/1445957545_501651.html>, fecha de consulta: 26 de agosto de 2018.

MORALES, M. (2017). «Los móviles disparan las consultas al Diccionario de la RAE el 58\% en 2016?», El País, 28 de enero de 2017 [en línea] <https://elpais. com/cultura/2017/01/27/actualidad/1485515637_238489.html $\gg$, fecha de consulta: 26 de agosto de 2018.

MURPHY, B. M. (2017). Key Concepts in Contemporary Popular Fiction. Edinburgh: Edinburgh University Press.

OXFORD (Gran Bretaña). «Bizarre» / «Bizarro», s. n., English Oxford Living Dictionaries. Oxford: Oxford University Press [en línea] <https://en.oxforddictionaries.com/definition/bizarre>, fecha de consulta: 26 de agosto de 2018.

RAE (@RAEinforma).«\#RAEconsultas: Aunque el DLE no recoge bizarro como 'raro', la extensión de este uso hace presagiar que se incluirá», Twitter, 2 de enero de 2017, hora 5:02 p.m.

RAE (@RAEinforma).«\#RAEconsultas: El desplazamiento semántico de bizarro en el español actual a 'raro, extravagante' se debe al influjo del inglés o el francés, y es especialmente frecuente en el español americano», Twitter, 22 de enero de 2018, hora 6:28 p.m.

RAE (@RAEinforma).«\#RAEconsultas: En español, bizarro es un préstamo del italiano [...]», Twitter, 30 de abril de 2018, hora 8:54 a.m. 
RAE (1726). Diccionario de Autoridades, Tomo primero (Letras A-B). Madrid: RAE [en línea] <http://web.frl.es/DA.html>, fecha de consulta: 26 de agosto de 2018.

RAE (2014a). Diccionario de la lengua española, 23aㅡ edición. Madrid: Espasa [en línea] <http://dle.rae.es/?w=diccionario>, fecha de consulta: 26 de agosto de 2018.

RAE (2014b). «La tecnología al servicio de la palabra. Últimos datos sobre consultas y accesos a los diccionarios, aplicaciones y formularios de la página web de la RAE», Boletín de información lingüística de la Real Academia Española (BILRAE), 5, febrero de 2014 [en línea] <http://revistas.rae.es/bilrae/issue/ view/14>, fecha de consulta: 26 de agosto de 2018.

RAE (2018). «El DLE en línea recibe 750 millones de consultas en 2017» [en línea] $<$ http://www.rae.es/noticias/el-dle-en-linea-recibe-750-millones-de-consultas-en-2017>, fecha de consulta: 26 de agosto de 2018.

RAE y ASALE (2005). Diccionario panhispánico de dudas. Madrid: Santillana [en línea] <http://www.rae.es/recursos/diccionarios/dpd>, fecha de consulta: 26 de agosto de 2018.

RODRÍGUEZ-PINA, G. (2016). «Por fin puedes usar bizarro para decir 'raro'», Verne. El País, 10 de noviembre de 2017 [en línea] <https://verne.elpais.com/ verne/2016/11/10/articulo/1478780253_802615.html>, fecha de consulta: 26 de agosto de 2018.

RUBIO HANCOCK, J. (2015). «La razón por la que bizarro es una de las palabras que más buscamos en el diccionario», Verne. El País, 8 de noviembre de 2015 [en línea] <https://verne.elpais.com/verne/2015/11/05/articulo/1446740407_989364.html>, fecha de consulta: 26 de agosto de 2018.

TOKARCZUK, O. (2018). Opowiadania bizarne. Kraków: Wydawnictwo Literackie.

TOKARCZUK, O. y KUBISIOWSKA, K. (2018). «Światy bizarne», Tygodnik Powszechny, 14, 26 de marzo de 2018 [también en línea] <https://www.tygodnikpowszechny.pl/swiaty-bizarne-152480>, fecha de consulta: 26 de agosto de 2018.

WIKIPEDIA [inglés]. «Bizarro» [en línea] <https://en.wikipedia.org/wiki/Bizarro $>$, fecha de consulta: 26 de agosto de 2018.

WIKIPEDIA [español]. «Bizarro (cómic)» [en línea] <https://es.wikipedia.org/ wiki/Bizarro_(c\%C3\%B3mic)>, fecha de consulta: 26 de agosto de 2018. 